\title{
IMPACT ANALYSIS OF CLIMATIC FACTORS ON VEGETATIVE GROWTH, YIELD AND COLD RESISTANCE OF OIL PALM INTRODUCED IN DIFFERENT REGIONS OF GUANGDONG PROVINCE, CHINA
}

\section{ZENG XIANHAI*; PAN DENGLANG**; LIN WEIFU‡ and LIU ZIFAN}

\begin{abstract}
Climatic data in six regions of Guangdong Province, China were collected and analysed with the traits observed from April 2010 to April 2015. Climatic factors showed significant regional and annual changes except annual rainfall (AR) in different studied regions. Annual sunshine hours (ASH) was negatively correlated with bunch number (NB), bunch weight ( $A B W$ ) and fresh fruit bunch (FFB) yield, but positively with abortion ratio of bunch (ABR). Furthermore, sex ratio of female inflorescences and bunches to total inflorescences and bunches (SR) had positive correlations with mean annual temperature (MAT) and extreme minimum temperature (EMT), while semi-lethal temperature $\left(L T_{50}\right)$ was positively correlated with $M A T$ and mean effective accumulated temperature above $10^{\circ} \mathrm{C}(M A A T)$, and negatively with AR. However, annual temperature of the coldest month (ATCM) was not significantly affected with other traits. ASH was the major determinant of $A B W, F F B$ and $A B R$, and $N B$ and $L T_{50}$ were mainly determined by MAAT. The major determining factor of frond production (FP) and fruit compaction rate (FCR) for MAT, and normal fruit weight per bunch (ANFW) for AR. Percentage of normal fruit weight to bunch weight (F/B) and abortion ratio of female inflorescence (RAFM) were mainly determined by ATCM, and SR by EMT.
\end{abstract}

Keywords: oil palm, vegetative growth, yield, cold resistance, climatic factor.

Date received: 11 June 2018; Sent for revision: 22 July 2018; Received in final form: 9 September 2018; Accepted: 8 January 2019.

\section{INTRODUCTON}

The shortage of edible oils in China due to serious competition between grain and oil crops for arable land has led to the import of huge volumes of vegetable fats, of which more than 5 million tonnes of palm oil has to be imported annually by China

Institute of Tropical Agriculture and Forestry, Hainan University, Haikou, Hainan 570228, P R China.

** Rubber Research Institute, Chinese Academy of Tropical Agricultural Sciences, Danzhou, Hainan 571737, P R China.

‡ Danzhou Germplasm Repository of Oil Palm of Ministry of Agriculture and Rural Affairs, Danzhou, Hainan 571737, P R China.

E-mail: jiangxilaobiao@163.com (https: / / apps.fas.usda.gov/psdonline/app/index. $\mathrm{html}$ / / app / downloads). Oil palm (Elaeis guineensis Jacq.), known as the king of the edible oils in the world, is the tropical oil crop with the largest production and the highest yield per unit area in the world, and it is also one of the important woody oil crops in the tropical regions of China in the future.

However, oil palm, as a typical tropical plant, generally grows at the latitude range from $12^{\circ} \mathrm{S}$ to $15^{\circ} \mathrm{N}$. Earlier studies (Corley and Tinker, 2003) showed that the ideal conditions for oil palm growth are annual rainfall of $2000-2500 \mathrm{~mm}$ at least 100 $\mathrm{mm}$ in each month, relative humidity above $85 \%$, low vapour pressure deficit, mean temperature of $22^{\circ} \mathrm{C}-33^{\circ} \mathrm{C}$, no extreme wind speed, sunshine of 5-7 
hr per day in all months and solar radiation of 15$17 \mathrm{MJ} \mathrm{m}^{-2}$ per day. So far, oil palm gives the highest oil yield with the average yield of $3.5 \mathrm{tha}^{-1} \mathrm{yr}^{-1}$ and the full yield potential estimated at 11-18 $\mathrm{t} \mathrm{ha}^{-1} \mathrm{yr}^{-1}$ under favourable conditions (Barcelos et al., 2015). The oil palm was introduced into China in 1926, and mainly distributed at between $18^{\circ} \mathrm{N}$ and $25^{\circ} \mathrm{N}$, the northern tropical regions with occasional damages by typhoon, cold and drought (Zeng et al., 2015; Cao et al., 2009). Zeng et al. (2015) reported that a large number of oil palms were scattered and planted as a landscape tree species in Guangdong, Yunnan, Hainan in China. These palms had undergone longterm natural domestication in the local climatic conditions and might have important beneficial variations for utilisation.

Much of the work was implemented on the effects of climate on growth and yield of oil palm. Low temperature has important effect on growth and yield of oil palm resulting in an increase of abortion, and slow vegetative growth and bunch ripening and restricts the geographical distribution. Earlier studies showed that a very little growth occurred at a mean temperature of $12^{\circ} \mathrm{C}$ (Ferwerda, 1977; $\mathrm{Lu}$ et al., 1982) and suggested extreme low temperature as an important reference factor for introduction and cultivation (Lu et al., 1991). Corley and Tinker (2003) reported that Tamatave in Madagascar has a particularly low minimum temperature around $18^{\circ} \mathrm{C}$ in four months, which produced a strongly seasonal yield pattern, and nearly $90 \%$ of the crop is harvested between June and December, owing to abortion and lower sex ratio in winter. Cao et al. (2009) revealed that the continuous low temperature weather of 32 days with mean temperature of $8^{\circ} \mathrm{C}-15^{\circ} \mathrm{C}$ and extreme minimum temperature of $5^{\circ} \mathrm{C}-8^{\circ} \mathrm{C}$ from 15 January 2008 to 25 February 2008 gave rise to cold injury in almost all of inflorescences and unripe bunches and a $20 \%$ decline in fresh fruit bunch (FFB) yield in this year.

It was not easy to accurately relate rainfall to oil palm growth and yields, but earlier studies (Corley and Tinker, 2003) generally considered that an additional water deficit of $100 \mathrm{~mm}$ in the year of harvest reduced the FFB yield by $10 \%-20 \%$ and the FFB yield was consequently both low and highly variable, with a very poor yield every $4-6$ years. Cao et al. (2009) noted an eight-month long drought with rainfall of 3.4-20.9 mm per month occurred in between September 2004 to April 2005 in Hainan, China, had caused a decrease of $38 \%-57 \%$ in frond production and lower the FFB yield via effects on floral initiation, sex differentiation, pollen quality and ripeness of fruit and bunch, etc. Sometimes sunshine hours are used as rough measure of solar radiation, because they are easier to measure than radiation, and they are normally well correlated. However, total sunshine hours per year have been correlated with annual yield, with a displacement of 28 months (Corley and Tinker, 2003). Earlier studies had usually shown numerous correlations between yield and climatic factors, but as Corley and Tinker (2003) noted, many of these are probably spurious, and few of these studies had added to the understanding of how yields were determined. There were few studies on cold resistance of oil palm, and people mostly focused on field investigation of cold damage, microstructure observation and determination of physiological and biochemical indexes. Zeng et al. (2016) had an evaluation of the vegetative growth, yield components and cold resistance traits in six regions (populations) at the latitude range between $20^{\circ} \mathrm{N}$ and $23^{\circ} \mathrm{N}$ in Guangdong Province, China during April 2010 to April 2015. This study reported that the higher the latitude the higher the bunch number and the lower the abortion ratio of female inflorescence to female inflorescence and fruit bunch.

In order to develop a series of cultivation techniques of oil palm in northern tropical environments in China, six oil palm populations (regions) in Guangdong, i.e. Dongguan, Maoming, Shenzhen, Huazhou, Zhanjiang and Leizhou, were selected for observation for five years, based on the results of the survey of oil palm germplasm resources introduced in Guangdong. Some analysis methods, i.e. analysis of variance, phenotypic correlation analysis and path coefficient analysis, were employed to compare the correlations between the traits of vegetative growth, yield and cold resistance in different populations and the meteorological variables collected from 2001 to 2016, and further analysed the major determining factors affecting the vegetative growth, yield and cold resistance of oil palm. The results are expected to provide some beneficial references for cultivation of oil palm in the northern tropical regions of China.

\section{MATERIALS AND METHODS}

A total of six oil palm populations were selected in February 2010 from Shenzhen, Dongguan, Maoming, Huazhou, Zhanjiang and Leizhou regions in Guangdong Province, China at between the latitude of $20^{\circ} \mathrm{N}$ and $23^{\circ} \mathrm{N}$. Each population was tagged with a region name, for example Shenzhen which indicates the population observed in Shenzhen region. Thirty-eight individual oil palm plants were selected as observation plants, of which 12 plants were in Shenzhen population, two in Dongguan, eight in Maoming, eight in Huazhou, five in Zhanjiang and three in Leizhou. Further geographical distribution information of oil palm populations on sites were mentioned in the article published by Zeng et al. (2016).

Climatic data with six parameters during the period between 2001 and 2016 in six regions 
were collected from the corresponding National Meteorological Stations of Guangdong Meteorology Disaster Prevention Technology Service Centre (Hereinafter referred to as GMDPTSC). The climatic parameters included mean annual temperature (MAT, $\left.{ }^{\circ} \mathrm{C}\right)$, annual sunshine hours (ASH, hr), annual rainfall $(\mathrm{AR}, \mathrm{mm})$, extreme minimum temperature $\left(\mathrm{EMT},{ }^{\circ} \mathrm{C}\right)$, annual temperature of the coldest month (ATCM, ${ }^{\circ} \mathrm{C}$ ), mean effective accumulated temperature above $10^{\circ} \mathrm{C}\left(\mathrm{MAAT},{ }^{\circ} \mathrm{C}\right)$. The regional climatic data, representing the data in populations, were used for statistical analysis with the mean value for 16 years.

Data of vegetative growth and yield traits in each population were collected based on the mean value of individual palm observed in respective population. Data collection on individual palm was initiated in April 2010, i.e. two months after selection, and then continued until April 2015 at a regular interval of three to six months, namely two to four times per year. Data on vegetative growth and yield traits including frond production (FP), total number of inflorescences (including male, female and bracts without anthesis inflorescences) and bunches (NIB), sex ratio (the percentage of total number of female inflorescences and bunches in total number of female, male inflorescences and bunches) (SR), female inflorescence abortion ratio (the percentage of the total number of aborted female inflorescences in total number of female inflorescences and bunches) (RAFM), bunch abortion ratio (the percentage of the total number of aborted bunches in total number of bunches) (ABR), FFB, fresh bunch number (NB), average bunch weight based on three fresh bunches per palm $(\mathrm{ABW})$, average fruit number per bunch (the total number of normal fruits and infertile fruits) (ANF), average normal fruit number per bunch (ANNF), average single fruit weight based on three fresh bunches per palm with 10 normal fruit per bunch (ASFW), fruit compact rate (the percentage of the total number of normal fruits to total number of fruits) (FCR), average normal fruit weight per bunch (ANFW), the percentage of ANFW in ABW $(\mathrm{F} / \mathrm{B})$, normal fruit yield (the product between ANFW and NB) (NFF), thickness ratio of shell to mesocarp (S/M), thickness ratio of shell to kernel $(\mathrm{S} / \mathrm{K})$, thickness ratio of mesocarp to kernel $(\mathrm{M} / \mathrm{K})$ were collected from April 2010 to April 2015. Some measurements of bunch and fruit quality such as the selection methods of fruits and the determination of ASFW using the 'bunch analysis' technique developed at the Nigerian Institute for Oil Palm Research (NIFOR) (Henson et al., 2004) were used in this study. The detailed determination methods and data could be found in the article published by Zeng et al. (2016).

Semi-lethal temperature $\left(\mathrm{LT}_{50}\right)$ was measured in April 2014 as cold-tolerance reference index. The healthy, intact leaflet on both sides of the middle leaf rachis of frond in the middle canopy toward sunny sides was selected as test materials. The detailed determination methods and data could be found in the article published by Zeng et al. (2016). Data of $\mathrm{LT}_{50}$ in each palm was the mean value of three repeated measurements, and the mean value of the measurement data of all plants in each population.

One-way repeated randomised block design analysis of variance (ANOVA) was used for the comparison of vegetative growth, yield and cold resistance traits of oil palm in different regions and climatic parameters in different regions and years. All results of ANOVA presented are the mean values \pm standard errors obtained from at least three replications.

Phenotypic correlation analysis was used to analyse the vegetative growth and yield-related traits, $\mathrm{LT}_{50}$ and climatic parameters in regions (populations).

Path coefficient analysis, developed by Wright (1923), was used to determine the interrelationships among all traits in a set of data, with soil FP, NIB, NB, ABW, FFB, NFF, ANF, ANNF, ASFW, ANFW, FCR, $\mathrm{F} / \mathrm{B}, \mathrm{SR}, \mathrm{S} / \mathrm{M}, \mathrm{S} / \mathrm{K}, \mathrm{M} / \mathrm{K}, \mathrm{RAFM}, \mathrm{ABR}$ and $\mathrm{LT}_{50}$ as the dependent variables and the climatic parameters as the independent variables. This method aids the partitioning and interpretation of cause-and-effect relationships among a set of variables. A direct casual effect $(p)$ of a trait on the dependent trait $(y)$ is indicated by a single one-directional path. Indirect causal effects are indicated by alternate paths from a trait to the dependent trait through another trait. Where $\mathrm{r}_{\mathrm{ij}}=$ correlation coefficient of trait $i$ with $j, \mathrm{i} \neq$ $\mathrm{j} ; \mathrm{p}_{\mathrm{iy}}=$ direct effect (or path coefficient) of trait $j$ on the end product, $\mathrm{y} ; \mathrm{r}_{\mathrm{ij}} \mathrm{p}_{\mathrm{jy}}=$ indirect effect (product of path coefficient along a given path).

Statistical analyses were conducted using the statistical software package DPS 7.05 for Windows XP (Tang et al., 2007).

\section{RESULTS AND DISCUSSION}

\section{Meteorological Conditions in Different Regions (Populations) in Guangdong Province, China}

The sites of national meteorological stations are very close to the corresponding populations of oil palm (Table 1), the data collected from meteorological stations can basically reflect the growth conditions of oil palm. The statistics from GMDPTSC in 2001-2016 showed the total average value of MAT, ASH, AR, EMT, ATCM and MAAT in oil palm populations were $23.27^{\circ} \mathrm{C}, 1887.11$ $\mathrm{hr}, 1797.05 \mathrm{~mm}, 5.37^{\circ} \mathrm{C}, 14.99^{\circ} \mathrm{C}$ and $8459.33^{\circ} \mathrm{C}$, respectively, and the EMT usually occurred between 17 December and 20 February of each year. Oil palm is one of typical tropical woody oil crops. Malaysia, as a major producer of palm oil, had the favourable 


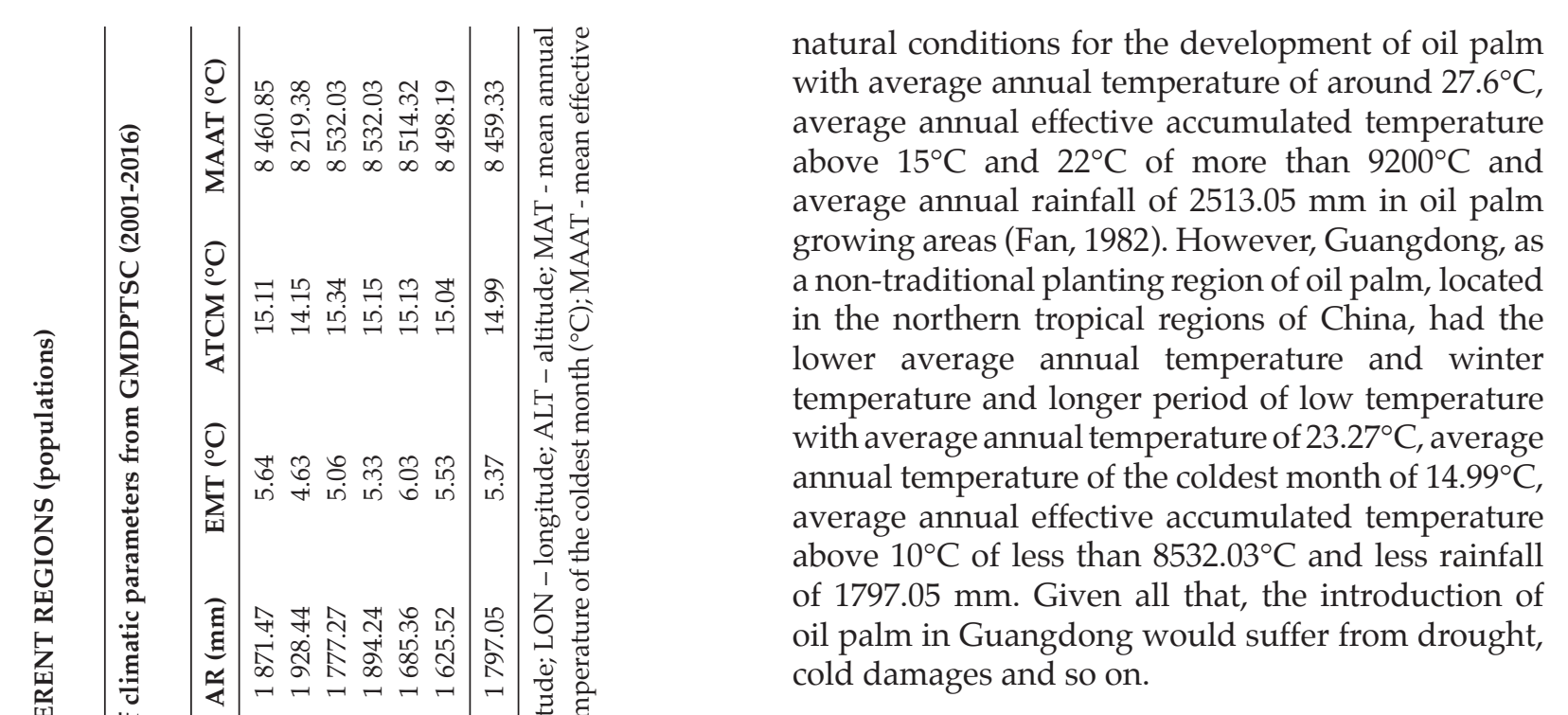

One-way ANOVA for Vegetative Growth, Yield and Cold Resistance Traits of Oil Palm in Different Regions

ANOVA regarding vegetative growth and yield traits showed that FP, NIB, NB, FFB, ANF, ANNF, $\mathrm{F} / \mathrm{B}, \mathrm{RAFM}, \mathrm{ABR}$ and $\mathrm{SR}$ had no significant regional variations (Table 2), but significant in other traits. The $\mathrm{LT}_{50}$, usually used as one of the indicators of cold resistance, was significantly less in Leizhou population than in other populations. Since there was no significant variation in NB in different populations, the highest NFF (the product between NB and ANFW) in Huazhou population was mainly attributed to the highest ANFW (2.43 kg per bunch), while in Maoming population with the highest FFB. Leizhou population had the lowest NFF and FFB with the lowest NB (3.34 bunches per plant), ABW (3.08 kg per bunch) and ANFW (0.66 kg per bunch). As two of important yield traits, the NFF, highly consistent with its composition, was more likely to reflect the effective yield level of oil palm than FFB, especially in the tropical region of China.

\section{One-way ANOVA for Climate Characters in Different Regions}

The ANOVA (Table 3) in climatic traits showed obvious significant differences among different regions (populations) except $\mathrm{AR}$ at the range with 1625.52-1928.44 mm. The MAT, ATCM and MAAT in Dongguan were the lowest in different regions $\left(22.84^{\circ} \mathrm{C}, 14.15^{\circ} \mathrm{C}\right.$ and $8219.38^{\circ} \mathrm{C}$, respectively), and significantly lower than other regions, while there was no significant difference among other regions. Leizhou had the highest ASH with 2068.11 $\mathrm{hr}$ and significantly higher than other regions, the lowest ASH appeared in Maoming with $1748.26 \mathrm{hr}$ and significantly lower than that in Leizhou and Dongguan, but there were no significant differences among Shenzhen, Dongguan, Huazhou and 


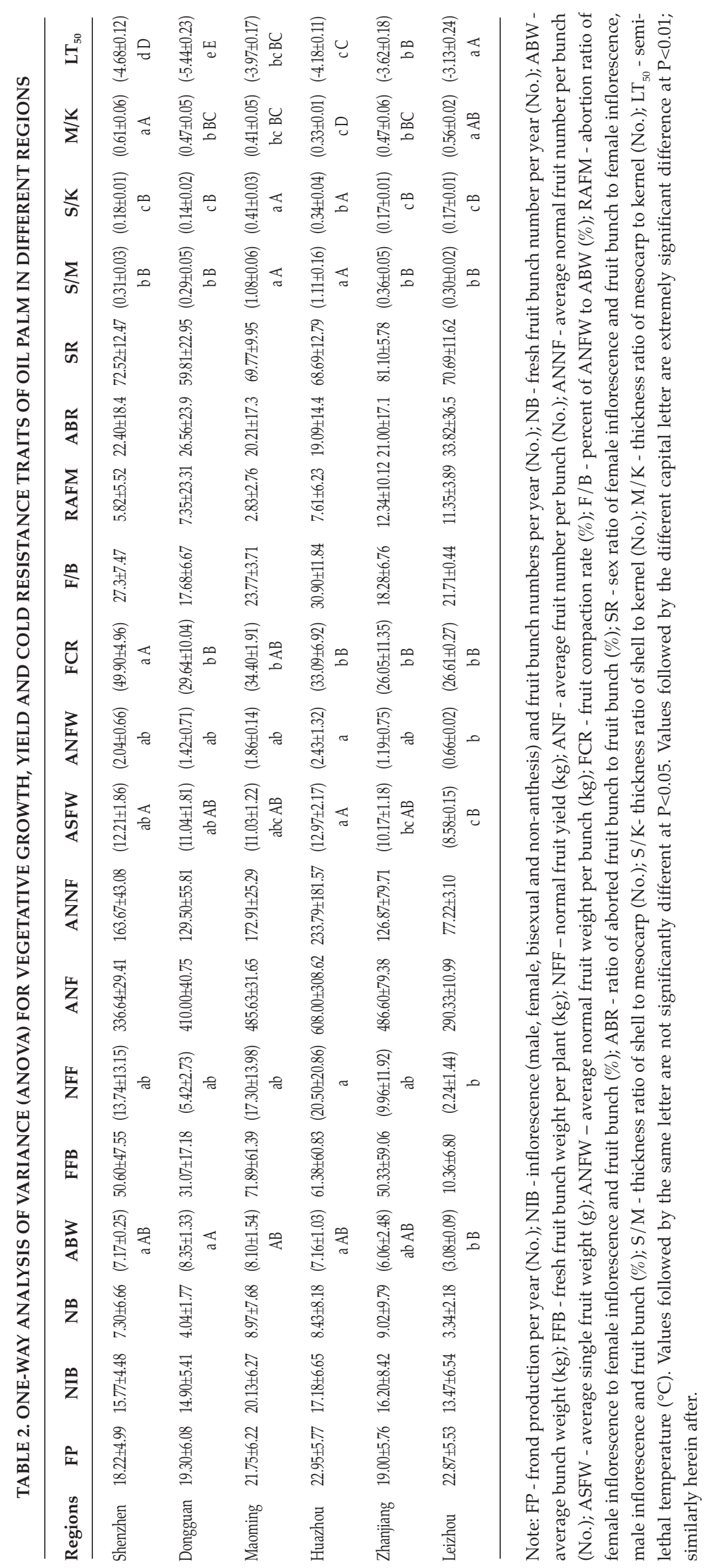


TABLE 3. ONE-WAY ANALYSIS OF VARIANCE (ANOVA) FOR CLIMATIC CHARACTERS IN DIFFERENT REGIONS

\begin{tabular}{|c|c|c|c|c|c|c|}
\hline Regions & $\operatorname{MAT}\left({ }^{\circ} \mathrm{C}\right)$ & ASH (hr) & $\mathrm{AR}(\mathrm{mm})$ & $\mathrm{EMT}\left({ }^{\circ} \mathrm{C}\right)$ & $\operatorname{ATCM}\left({ }^{\circ} \mathrm{C}\right)$ & MAAT $\left({ }^{\circ} \mathrm{C}\right)$ \\
\hline \multirow[t]{2}{*}{ Shenzhen } & $(23.33 \pm 0.37)$ & $(1867.08 \pm 146.76)$ & $1871.47 \pm 470.76$ & $(5.64 \pm 1.77)$ & $(15.11 \pm 1.37)$ & $(8460.85 \pm 537.37)$ \\
\hline & a A & bc BC & & $\mathrm{ab} A B$ & a A & a A \\
\hline \multirow[t]{2}{*}{ Dongguan } & $(22.84 \pm 0.42)$ & (1 920.45 \pm 187.48$)$ & $1928.44 \pm 353.31$ & $(4.63 \pm 1.64)$ & $(14.15 \pm 1.56)$ & (8 219.38 \pm 496.67$)$ \\
\hline & b B & $\mathrm{b} A B$ & & c B & b B & $\mathrm{bB}$ \\
\hline \multirow[t]{2}{*}{ Maoming } & $(23.38 \pm 0.44)$ & $(1748.26 \pm 243.03)$ & $1777.27 \pm 529.70$ & $(5.06 \pm 1.41)$ & $(15.34 \pm 1.59)$ & $(8532.03 \pm 472.92)$ \\
\hline & a A & с C & & bc $A B$ & a A & a A \\
\hline \multirow[t]{2}{*}{ Huazhou } & $(23.34 \pm 0.38)$ & $(1860.51 \pm 205.87)$ & $1894.24 \pm 503.74$ & $(5.33 \pm 1.31)$ & $(15.15 \pm 1.39)$ & $(8531.21 \pm 433.85)$ \\
\hline & a A & bc BC & & $a b c A B$ & a A & a A \\
\hline \multirow[t]{2}{*}{ Zhanjiang } & $(23.38 \pm 0.58)$ & $(1858.25 \pm 147.61)$ & $1685.36 \pm 389.98$ & $(6.03 \pm 1.28)$ & $(15.13 \pm 1.57)$ & $(8514.32 \pm 472.47)$ \\
\hline & a A & bc BC & & a A & a A & a A \\
\hline \multirow[t]{2}{*}{ Leizhou } & $(23.32 \pm 0.50)$ & $(2068.11 \pm 147.51)$ & $1625.52 \pm 466.50$ & $(5.52 \pm 1.38)$ & $(15.04 \pm 1.61)$ & $(8498.19 \pm 473.55)$ \\
\hline & a A & a A & & $\mathrm{ab} A B$ & a A & a A \\
\hline
\end{tabular}

Note: MAT - mean annual temperature $\left({ }^{\circ} \mathrm{C}\right)$; ASH - annual sunshine hours (hr); AR - annual rainfall (mm); EMT - extreme minimum temperature $\left({ }^{\circ} \mathrm{C}\right)$; ATCM - annual temperature of the coldest month $\left({ }^{\circ} \mathrm{C}\right)$; MAAT - mean effective accumulated temperature above $10^{\circ}\left({ }^{\circ} \mathrm{C}\right)$; Each value is presented by the mean values \pm standard errors. Values followed by the same letter are not significantly different at $\mathrm{P}<0.05$. Values followed by the different small letter are significantly different at $\mathrm{P}<0.05$. Values followed by the different capital letter are extremely significant difference at $\mathrm{P}<0.01$; similarly herein after.

Zhanjiang regions. Zhanjiang had the highest EMT with $6.03^{\circ} \mathrm{C}$ and significantly higher than that in Maoming and Dongguan. However, Dongguan had the lowest EMT with $4.63^{\circ} \mathrm{C}$ and significantly lower than that in Zhanjiang, Shenzhen and Leizhou regions.

The trend of annual climate changes was consistent and stable, but the annual variations were obvious and the range of annual changes was large, which indicated high variability among years (Table 4). The MAT and ATCM decreased significantly in 2008 and 2011, especially in Donguan with the largest drop. The AR decreased significantly in 2004, of which Leizhou was the largest. The EMT occurred in 2005 and 2010 and was the lowest in Dongguan. The highest ASH reached $2215.78 \mathrm{hr}$ in 2003 and the lowest was $1646.87 \mathrm{hr}$ in 2012. The MAAT could reach up to $9093.42^{\circ} \mathrm{C}$ in 2003 and decrease to $7645.58^{\circ} \mathrm{C}$ in 2010 .

\section{Phenotypic Correlation Analysis}

Phenotypic correlation analyses were carried out for all the traits in different populations (Table 5). The interpretation of the strength of a relationship is based on correlation of coefficient $(r)$. Cohen (1988) estimated the $r \geq 0.70$ as very high relationship, 0.69 $<\mathrm{r}>0.50$ as high, $0.49<\mathrm{r}>0.30$ as moderate and 0.29 $<\mathrm{r} \geq 0.10$ as low. Significant associations occurred in many cases, but only those involving MAT, ASH, AR, EMT, ATCM, MAAT, FFB, NFF, NB, ABW and ANFW in relation to other traits will be discussed.

Among meteorological factors, some were highly dependant on each other, the results from Table 5 showed the significant positive relationships among MAT, ATCM and MAAT, such as MAT and
$\operatorname{ATCM}\left(r=0.99^{* *}\right)$, MAT and MAAT $\left(r=0.98^{* *}\right)$, ATCM and MAAT $\left(r=0.98^{* *}\right)$. In addition, the meteorological factors were closely related to the vegetative growth, yield and cold resistance traits. The MAT and EMT gave significant positive relationships with SR $\left(\mathrm{r}=0.79^{*}\right.$ and $0.95^{* *}$, respectively). In addition, the MAT and MAAT had significant positive relationships with $\mathrm{LT}_{50}(\mathrm{r}$ $=0.76^{*}$ and $0.79^{*}$, respectively). However, the ASH showed significant negative relationships with NIB $\left(r=-0.92^{* *}\right)$, NB $\left(r=-0.85^{*}\right)$, ABW $\left(r=-0.79^{*}\right)$, FFB $\left(\mathrm{r}=-0.96^{* *}\right)$ and NFF $\left(\mathrm{r}=-0.80^{*}\right)$, but a significant positive relationship with $\mathrm{ABR}\left(\mathrm{r}=0.91^{* *}\right)$. The AR had significant positive relationship with $A B W$ $\left(\mathrm{r}=0.82^{*}\right)$ and ASFW $\left(\mathrm{r}=0.84^{*}\right)$, but negatively related with $\operatorname{LT}_{50}\left(\mathrm{r}=-0.91^{* *}\right)$.

The analysis showed FFB was positively correlated with NIB, NB, NFF, ANNF, ANFW, S/K $\left(\mathrm{r}=0.92^{* *}, 0.92^{* *}, 0.92^{* *}, 0.81^{*}, 0.79^{*}\right.$ and $0.76^{*}$, respectively) and negatively correlated with ABR and $\mathrm{ASH}$ in populations $\left(\mathrm{r}=-0.95^{* *}\right.$ and $-0.96^{* *}$, respectively). The NB, as one of the FFB or NFF yield components, had significant positive correlations with NIB, FFB and NFF $\left(\mathrm{r}=0.80^{*}, 0.92^{* *}\right.$ and $0.83^{*}$, respectively), but significant negative correlations with ABR and ASH ( $\mathrm{r}=-0.92^{* *}$ and $-0.85^{*}$, respectively). However, the $\mathrm{ABW}$ had significant negative relationship with $\mathrm{LT}_{50}$ and $\mathrm{ASH}$ (both $\mathrm{r}=$ - $\left.0.79^{*}\right)$ and positively with $\mathrm{AR}\left(\mathrm{r}=0.82^{*}\right)$, but no significant relationships with $\mathrm{NB}, \mathrm{FFB}$ and other vegetative growth and yield traits in agreement with previous studies (Zeng et al., 2016). The NFF, as one of evaluation forms for fresh fruit yield in this study, is the product between NB and ANFW. The observations based on oil palm populations showed NFF was positively correlated with NIB, NB, FFB, 
TABLE 4. ONE-WAY ANALYSIS OF VARIANCE (ANOVA) FOR CLIMATIC CHARACTERS IN ANNUAL CHANGES

\begin{tabular}{|c|c|c|c|c|c|c|}
\hline Year & MAT $\left({ }^{\circ} \mathrm{C}\right)$ & ASH (hr) & $\mathrm{AR}(\mathrm{mm})$ & EMT $\left({ }^{\circ} \mathrm{C}\right)$ & ATCM $\left({ }^{\circ} \mathrm{C}\right)$ & MAAT $\left({ }^{\circ} \mathrm{C}\right)$ \\
\hline \multirow[t]{2}{*}{2000} & $(23.53 \pm 0.34)$ & $(1933.42 \pm 187.86)$ & $(1873.60 \pm 364.43)$ & $(6.73 \pm 1.14)$ & $(15.80 \pm 0.80)$ & $(8693.52 \pm 72.35)$ \\
\hline & bcd ABC & bcd ABCD & abcde ABCD & abc ABC & cd BCDE & bc BCDE \\
\hline \multirow[t]{2}{*}{2001} & $(23.53 \pm 0.27)$ & $(1803.60 \pm 199.72)$ & $(2412.45 \pm 248.75)$ & $(6.77 \pm 1.18)$ & $(16.80 \pm 0.45)$ & $(8607.65 \pm 103.33)$ \\
\hline & bcd ABC & cde BCDE & a A & abc ABC & a A & bcd CDE \\
\hline \multirow[t]{2}{*}{2002} & $(23.73 \pm 0.24)$ & $(1839.65 \pm 163.86)$ & (2 310.25 \pm 540.83$)$ & $(5.00 \pm 0.38)$ & $(16.63 \pm 0.54)$ & $(8635.40 \pm 105.94)$ \\
\hline & $\mathrm{ab} A B$ & bcde BCDE & $\mathrm{ab} A B$ & de CDEF & $\mathrm{ab} A B$ & bcd CDE \\
\hline \multirow[t]{2}{*}{2003} & $(23.72 \pm 0.45)$ & (2 215.78 \pm 138.62$)$ & (1 378.15 \pm 151.48$)$ & $(4.70 \pm 0.90)$ & $(15.45 \pm 0.50)$ & $(9093.42 \pm 275.46)$ \\
\hline & abc AB & a A & de D & def DEF & de CDE & a A \\
\hline \multirow[t]{2}{*}{2004} & $(23.25 \pm 0.31)$ & (2 090.78 \pm 104.03$)$ & (1 264.25 \pm 291.37$)$ & $(4.73 \pm 0.95)$ & $(15.32 \pm 0.71)$ & (7 950.72 \pm 111.16$)$ \\
\hline & de BC & $\mathrm{ab} A B$ & e D & def DEF & de DE & fg GH \\
\hline \multirow[t]{2}{*}{2005} & $(23.15 \pm 0.27)$ & $(1703.48 \pm 121.02)$ & $(1642.35 \pm 360.45)$ & $(4.35 \pm 1.47)$ & $(15.43 \pm 0.78)$ & $(8$ 198.38 \pm 469.80$)$ \\
\hline & de C & de DE & de BCD & def DEF & de CDE & ef FG \\
\hline \multirow[t]{2}{*}{2006} & $(23.37 \pm 0.34)$ & $(1761.77 \pm 143.55)$ & $(1663.50 \pm 466.08)$ & $(5.95 \pm 0.85)$ & $(16.25 \pm 0.37)$ & $(8535.48 \pm 124.30)$ \\
\hline & bcde BC & cde CDE & cde BCD & bcd ABCD & abc ABC & cd DEF \\
\hline \multirow[t]{2}{*}{2007} & $(23.30 \pm 0.23)$ & $(1946.55 \pm 113.52)$ & (1 532.73 \pm 183.38$)$ & $(7.02 \pm 1.27)$ & $(14.97 \pm 0.40)$ & $(8905.73 \pm 100.54)$ \\
\hline & cde BC & bcd ABCD & de D & $\mathrm{ab} A B$ & ef EF & $\mathrm{ab} A B C D$ \\
\hline \multirow[t]{2}{*}{2008} & $(22.52 \pm 0.21)$ & $(1852.90 \pm 164.58)$ & $(2323.60 \pm 490.97)$ & $(5.27 \pm 0.33)$ & $(12.27 \pm 0.39)$ & $(7956.60 \pm 82.96)$ \\
\hline & fD & bcde BCDE & $\mathrm{ab} \mathrm{AB}$ & cde BCDE & h G & $\mathrm{fg} \mathrm{GH}$ \\
\hline \multirow[t]{2}{*}{2009} & $(23.15 \pm 0.21)$ & (1 936.12士138.58) & $(1778.27 \pm 204.13)$ & $(5.08 \pm 1.38)$ & $(13.68 \pm 0.52)$ & $(8936.40 \pm 184.18)$ \\
\hline & de C & bcd ABCDE & bcde ABCD & cde BCDEF & $g G$ & $\mathrm{ab} \mathrm{ABC}$ \\
\hline \multirow[t]{2}{*}{2010} & $(23.08 \pm 0.37)$ & $(1778.17 \pm 179.69)$ & (1 892.33 \pm 171.91$)$ & $(3.12 \pm 0.86)$ & $(16.42 \pm 0.71)$ & $(7645.58 \pm 103.18)$ \\
\hline & e C & cde CDE & abcd $A B C D$ & $\mathrm{fF}$ & abc $A B$ & $\mathrm{~g} \mathrm{H}$ \\
\hline \multirow[t]{2}{*}{2011} & $(22.42 \pm 0.26)$ & $(1889.03 \pm 202.45)$ & 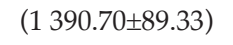 & $(4.38 \pm 0.73)$ & $(11.85 \pm 0.65)$ & $(8345.12 \pm 388.84)$ \\
\hline & f D & bcde BCDE & de D & def DEF & h H & de EF \\
\hline \multirow[t]{2}{*}{2012} & $(23.13 \pm 0.28)$ & $(1646.87 \pm 163.67)$ & $(1789.47 \pm 252.28)$ & $(5.18 \pm 0.62)$ & $(13.72 \pm 0.69)$ & $(8175.62 \pm 203.70)$ \\
\hline & de C & e E & bcde ABCD & cde BCDE & $\mathrm{g} \mathrm{G}$ & ef FG \\
\hline \multirow[t]{2}{*}{2013} & $(23.07 \pm 0.18)$ & $(1822.98 \pm 110.18)$ & (2 275.22 \pm 199.33 ) & $(5.97 \pm 0.63)$ & $(14.35 \pm 0.46)$ & $(9072.53 \pm 84.69)$ \\
\hline & e C & cde BCDE & abc ABC & bcd ABCD & fg FG & a $\mathrm{AB}$ \\
\hline \multirow[t]{2}{*}{2014} & $(23.28 \pm 0.23)$ & (1 966.25 \pm 127.43$)$ & (1 637.88 \pm 214.02$)$ & $(3.82 \pm 0.84)$ & $(14.93 \pm 0.39)$ & $(7823.90 \pm 77.21)$ \\
\hline & de BC & abc ABCD & de BCD & ef EF & ef EF & $\mathrm{g} G H$ \\
\hline \multirow[t]{2}{*}{2015} & $(24.02 \pm 0.29)$ & $(2006.40 \pm 229.09)$ & $(1588.05 \pm 427.28)$ & $(7.82 \pm 0.74)$ & $(15.92 \pm 0.28)$ & $(8773.22 \pm 101.82)$ \\
\hline & a A & $a b c A B C$ & de CD & a A & bcd ABCD & abc ABCD \\
\hline
\end{tabular}

Note: MAT - mean annual temperature $\left({ }^{\circ} \mathrm{C}\right)$; ASH - annual sunshine hours (hr); AR - annual rainfall (mm); EMT - extreme minimum temperature $\left({ }^{\circ} \mathrm{C}\right)$; ATCM - annual temperature of the coldest month $\left({ }^{\circ} \mathrm{C}\right)$; MAAT - mean effective accumulated temperature above $10^{\circ}\left({ }^{\circ} \mathrm{C}\right)$

ANF, ANNF, ASFW, ANFW, F/B, S/M and S/K $\left(\mathrm{r}=0.80^{*}, 0.83^{*}, 0.92^{* *}, 0.75^{*}, 0.95^{* *}, 0.82^{*}, 0.91^{* *}\right.$, $0.76^{*}, 0.84^{*}$ and $0.80^{*}$, respectively), but negatively correlated with $\mathrm{ABR}\left(\mathrm{r}=-0.89^{* *}\right)$ and $\mathrm{ASH}(\mathrm{r}=$ $\left.-0.80^{\star}\right)$. The ANFW, as the other component of NFF yield, showed significant positive relationships with FFB, NFF, ANNF and ASFW $\left(r=0.79^{*}, 0.91^{* *}, 0.97^{* *}\right.$ and $0.97^{*}$, respectively), while negatively with $A B R$ $\left(\mathrm{r}=-0.81^{*}\right)$.

Changes in FFB or NFF yield were always due to changes in one or other of the yield components, $\mathrm{NB}, \mathrm{ABW}$ and ANFW, so understanding the effects of environment on these components would help in explaining yield fluctuations. According to the results of correlation analysis, ASH was closely related to $\mathrm{NB}$ and $\mathrm{ABW}$ with the higher $\mathrm{ASH}$ the lower NB and $\mathrm{ABW}$, and the differences in yields were primarily due to the changes in ASH. The results deduced that the correlations of ASH with fruiting activity and yields indicated the higher
ASH and the higher ABR, which in turn resulted in the lower NB and further gave a decrease effect on FFB and NFF yields, and the conclusion was different from other authors (Corley, 1992; Corley and Breure, 1992), who suggested that abortion rate was higher during periods of high activity with high NB. The NFF instead of FFB, as a yield evaluation index maybe better to reflect the environmental adaptation requirements, especially in the northern tropical regions in China, owing to both NB and ANFW were positively related to NFF. The $\mathrm{LT}_{50}$ was usually used as the identification index for cold resistance, indicating the lower $\mathrm{LT}_{50}$ the stronger cold resistance, had significant negative correlation with $\mathrm{ABW}$, but no significant correlation with the others. The results showed that the lower MAT and MAAT were beneficial to the improvement of the cold resistance in oil palm populations, and the stronger cold resistance would increase the ABW. 


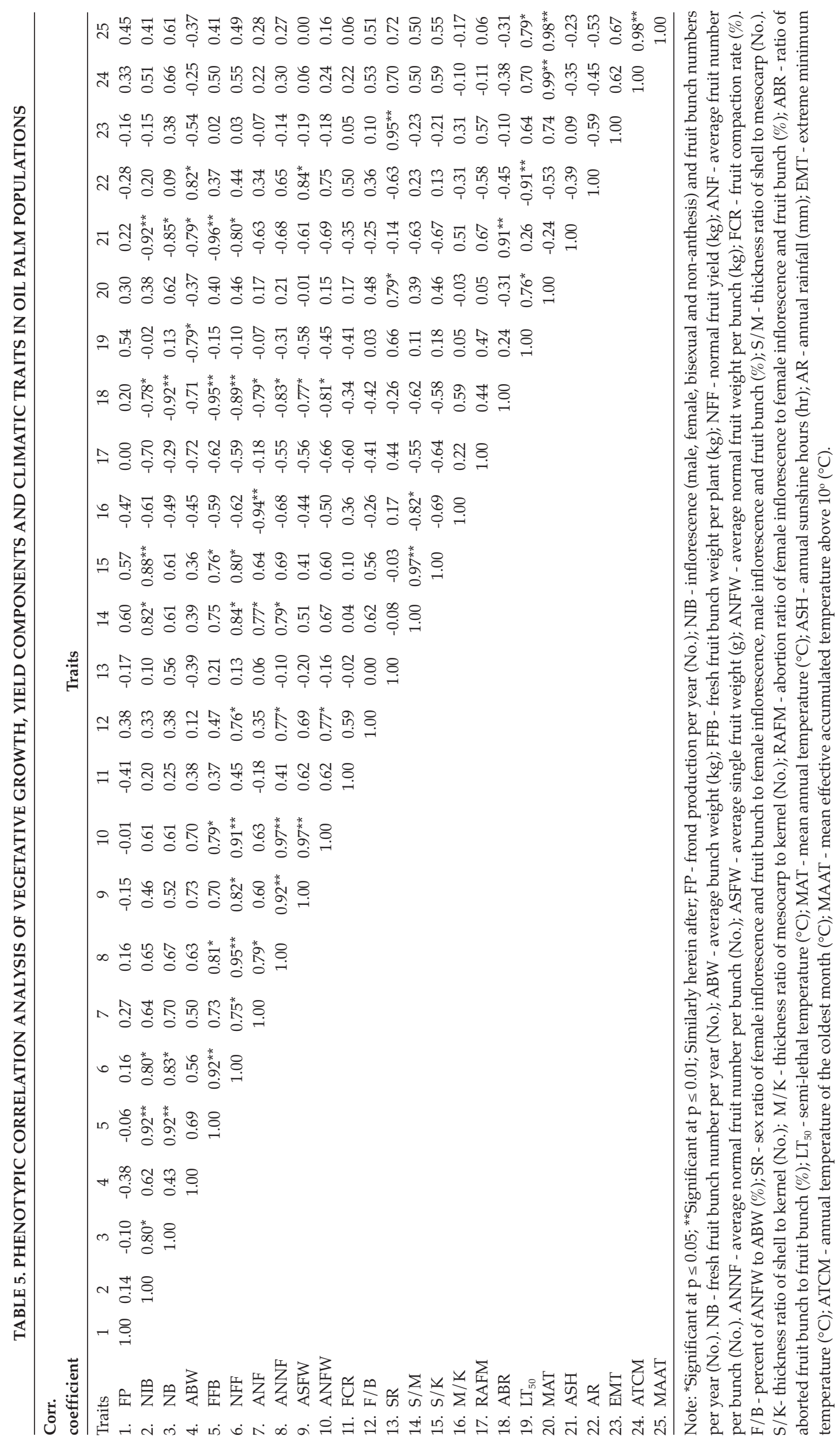




\section{Path Coefficient Analysis from Stepwise Regression Analysis}

Path coefficient analysis was used to further investigate the major climatic factors affecting the vegetative growth, yield and cold resistance traits in different oil palm populations. The higher determining coefficient and lower residual path coefficient indicated that the higher percentage of variation in a trait was determined by some determinants (climatic factors).

The ASH played the most important roles on NIB, $\mathrm{ABW}, \mathrm{FFB}$ and $\mathrm{ABR}$, and had the highest negative direct effect on NIB, ABW and FFB $\left(\mathrm{p}_{1 \mathrm{v}}=-0.845, \mathrm{p}_{2 \mathrm{y}}\right.$ $=-0.758$ and $p_{1 y}=-0.834$, respectively) (Table 6), but positive direct effect on ABR $\left(\mathrm{p}_{1 \mathrm{y}}=0.730\right)$ (Table 7), which indicated the higher ASH caused the lower inflorescence number and the higher bunch failure, and thus the decrease of bunch weight and FFB yield. Moreover, the ASH had very highly negative correlations with NIB, ABW and FFB ( $\mathrm{r}=-0.92^{* *}$, $r=-0.79^{*}$ and $r=-0.96^{* *}$, respectively). Unlike ASH, the MAAT had the highest positive direct effect on $\mathrm{NFF}$ and $\mathrm{NB}\left(\mathrm{p}_{4 \mathrm{y}}=1.405\right.$ and $\mathrm{p}_{4 \mathrm{y}}=1.176$, respectively) (Table 7). Since NFF is a composite of ANFW and $\mathrm{NB}$, the higher MAAT would increase the NB, thus increasing the fresh fruit yield. The MAAT was also the determinant of fruit number traits including ANF and ANNF with the highest direct effect $\left(\mathrm{p}_{4 \mathrm{y}}=\right.$ 4.370 and $\mathrm{p}_{4 \mathrm{y}}=1.869$, respectively) (Table 8) and some fruit components such as S/M, S/K and M/K with the highest direct effect $\left(\mathrm{p}_{4 \mathrm{y}}=2.913, \mathrm{p}_{4 \mathrm{y}}=1.519\right.$ and $\mathrm{p}_{4 \mathrm{y}}=-4.655$, respectively) (Tables 8 and 9). Analysis from Table 9 showed that MAAT played a decisive role in the cold resistance of oil palm populations, and had the largest positive direct effect $\left(\mathrm{p}_{4 \mathrm{y}}=1.365\right)$, the ATCM had the largest negative direct effect ( $\mathrm{p}_{1 \mathrm{y}}$ $=-0.851$ ). In addition, the MAAT was significantly positively correlated with the cold resistance of oil palm population $\left(\mathrm{r}=0.79^{*}\right)$, which is the main meteorological factor conducive to the improvement of the cold resistance in oil palm populations. The MAT had no significant correlations with FP and FCR, but was considered to be the determining factors on both of them with the highest negative direct effect on FP $\left(p_{1 y}=-6.174\right)$ and positive direct effect on FCR $\left(p_{1 y}=5.005\right)$ (Table 10), which showed that the higher MAT could not promote the frond production and the higher annual temperature could increase the fruit-bearing rate. Although there was no significant correlation between ATCM and any of the other vegetative traits, the ATCM played an important role in determining $\mathrm{F} / \mathrm{B}$ and RAFM with the highest positive direct effect of $\mathrm{p}_{4 y}=1.432$ (Tables 10 and 11) and the highest negative direct effect of $\mathrm{p}_{3 \mathrm{y}}=-2.809$ (Table 10), respectively. ANFW depends on ANNF and ASFW, the ASFW was closely related to AR $\left(r=0.84^{*}\right)$ and, together with ANFW, was mainly determined by AR $\left(p_{2 y}=1.240\right.$

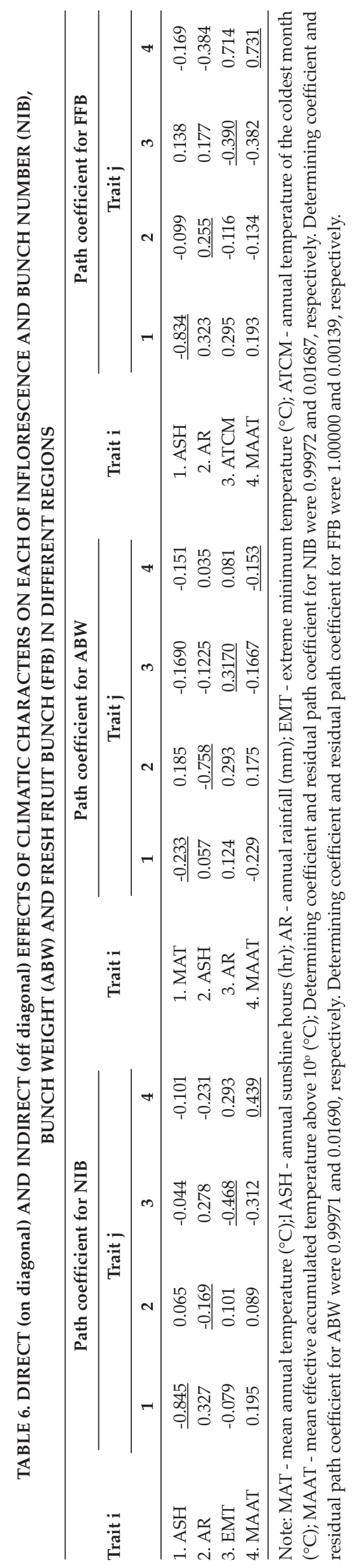



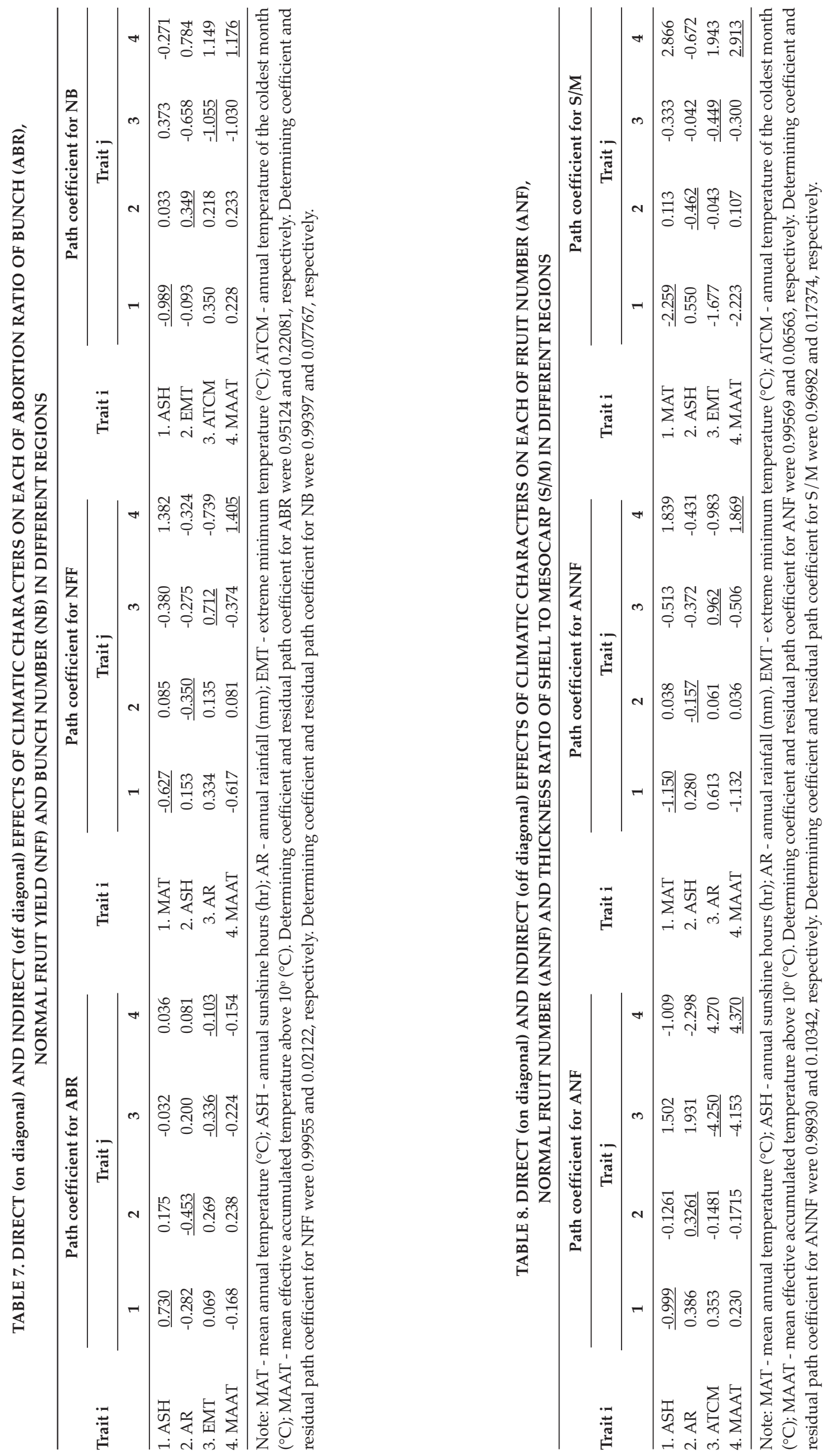

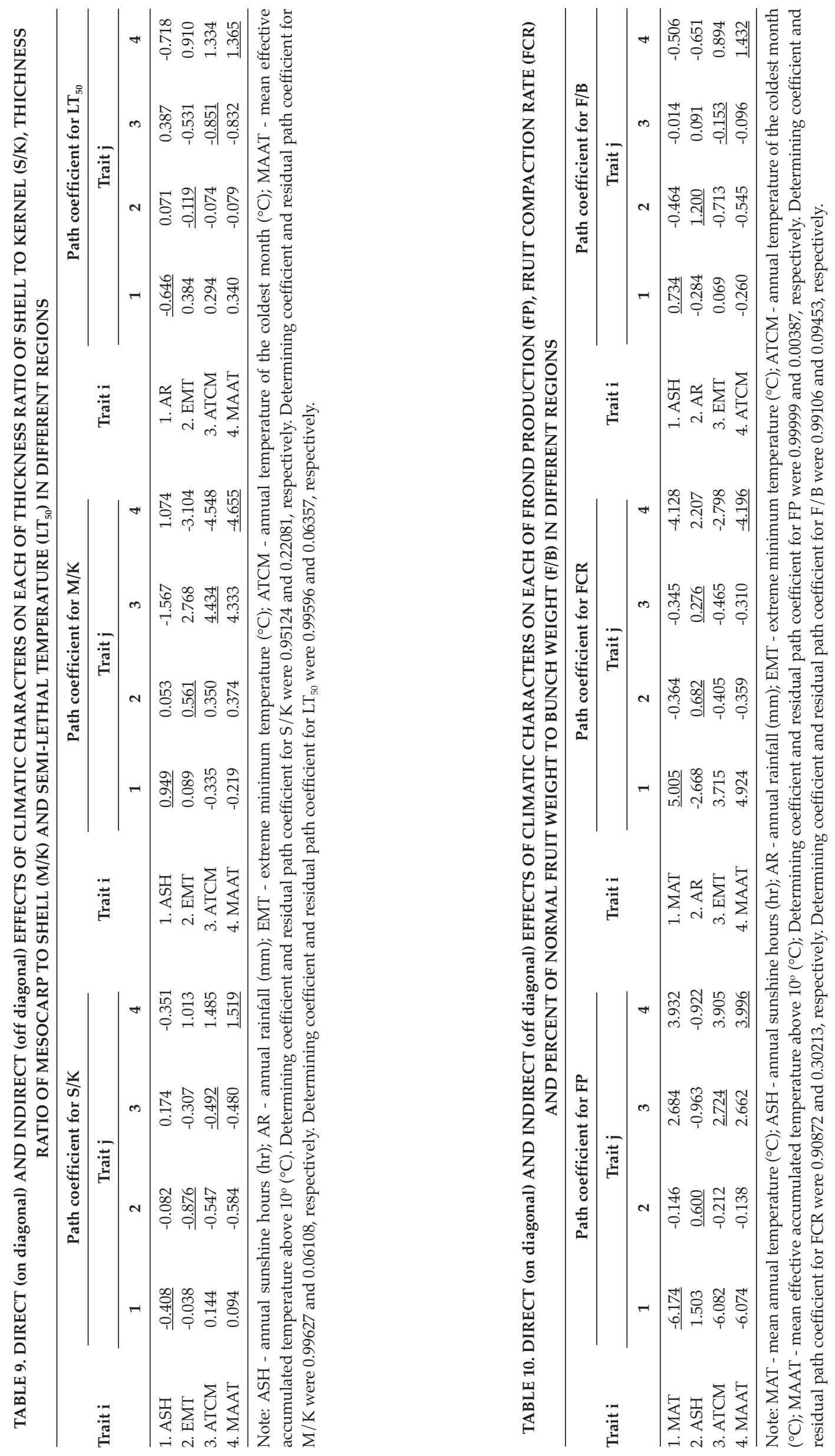


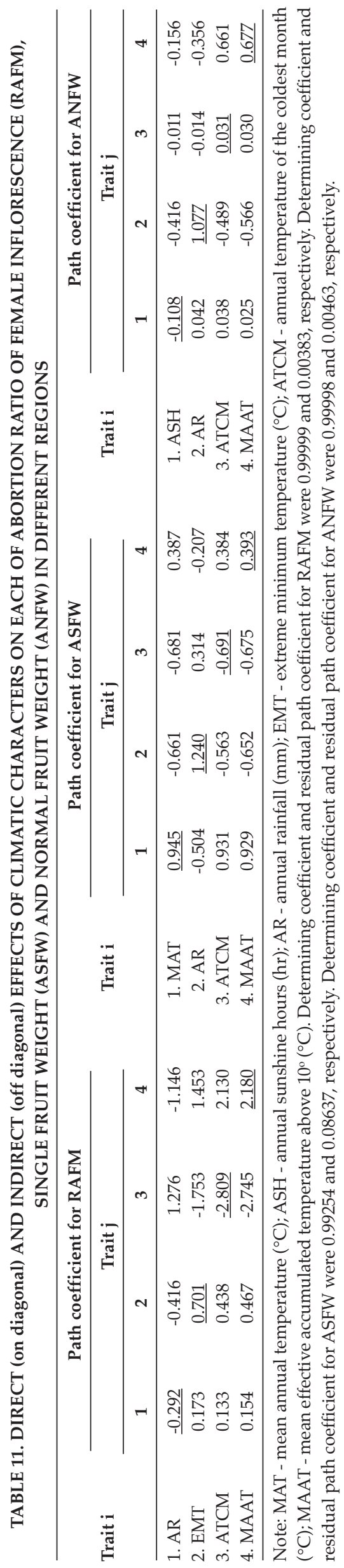

and $p_{2 y}=1.077$, respectively) (Table 11). SR was an important factor in the seasonal variation of $\mathrm{NB}$, but there was no clear answer as to what factors affect the true changes in SR (Corley and Tinker, 2003). The results from Table 12 showed that EMT had the highest direct effect on SR $\left(\mathrm{p}_{3 \mathrm{y}}=0.8757\right)$ and the highest positive relationship $\left(\mathrm{r}=0.99^{* *}\right)$, followed by ASH $\left(\mathrm{p}_{1 \mathrm{y}}=-0.396\right)$.

TABLE 12. DIRECT (on diagonal) AND INDIRECT (off diagonal) EFFECTS OF CLIMATIC CHARACTERS ON SEX RATIO (SR) IN DIFFERENT REGIONS

\begin{tabular}{lcccc}
\hline & \multicolumn{4}{c}{ Path coefficient for SR } \\
\cline { 2 - 5 } Trait i & \multicolumn{4}{c}{ Trait $\mathbf{j}$} \\
\cline { 2 - 5 } & $\mathbf{1}$ & $\mathbf{2}$ & $\mathbf{3}$ & $\mathbf{4}$ \\
\hline 1. ASH & $\underline{-0.396}$ & 0.124 & 0.082 & 0.046 \\
2. AR & 0.153 & $\underline{-0.321}$ & -0.520 & 0.059 \\
3. EMT & -0.037 & 0.191 & $\underline{0.876}$ & -0.080 \\
4. ATCM & 0.140 & 0.146 & 0.547 & $\underline{-0.129}$ \\
\hline
\end{tabular}

Note: ASH - annual sunshine hours (hr); AR - annual rainfall $(\mathrm{mm})$; EMT - extreme minimum temperature $\left({ }^{\circ} \mathrm{C}\right)$; ATCM annual temperature of the coldest month $\left({ }^{\circ} \mathrm{C}\right)$. Determining coefficient and residual path coefficient for SR were 0.99976 and 0.01564 , respectively.

\section{CONCLUSION}

In this study, the variations in all meteorological factors in six oil palm populations (regions) appeared to have significant annual differences, and some factors, such as MAT, ASH, EMT, ATCM and MAAT, showed strong inter-regional changes except AR. However, oil palm introduced in Guangdong, China, growing outside the usual oil palm regions, would suffer from less favourable climatic circumstances such as drought with the lower AR of $1797.05 \mathrm{~mm}$ and higher ASH of $1887.11 \mathrm{hr}$, and low temperatures with the lower MAT of $23.27^{\circ} \mathrm{C}$, EMT of $5.37^{\circ} \mathrm{C}$, ATCM of $14.99^{\circ} \mathrm{C}$ and MAAT of $8459.33^{\circ} \mathrm{C}$, etc.

Phenotypic correlation analysis showed MAT, ASH, AR, EMT and MAAT were closely related to vegetative growth, yield and cold resistance traits in oil palm populations except ATCM. MAT was positively correlated with $\mathrm{SR}$ and $\mathrm{LT}_{50}$. ASH was negatively correlated with $\mathrm{NIB}, \mathrm{NB}, \mathrm{ABW}, \mathrm{FFB}$ and NFF, but negatively correlated with ABR. AR was negatively correlated with $\mathrm{LT}_{50}$ and positively correlated with ABW and ASFW. Although there were significant correlations among EMT, MAAT and ATCM, EMT and MAAT had significant positive correlations with $\mathrm{SR}$ and $\mathrm{LT}_{50}$, respectively. However, ATCM had no significant correlation with other traits in oil palm populations.

Path coefficient analysis further revealed that MAT was the major determining factor in both FP and FCR with the highest negative and positive 
direct effect, respectively. ASH was the most important factor in the determination of NIB, ABW and FFB with the highest negative direct effect and ABR with the highest positive direct effect. MAAT was the major determining factor with the highest positive direct effect on NB, NFF, ANF, ANNF, S/M, $\mathrm{S} / \mathrm{K}$ and $\mathrm{LT}_{50}$, but with the highest negative direct effect on $\mathrm{M} / \mathrm{K}$. AR had the predominant influence on ASFW and ANFW with the highest positive direct effect. ATCM mainly determined the F/B and RAFW with the highest positive and negative direct effect, respectively. EMT was the principle influencing factor on SR with the highest positive direct effect. The results indicated the higher $\mathrm{ASH}$, which was likely to prolong the growth period through the low temperature and drought period in winter and spring seasons easily resulting in the deficiency of solar heat quantity in the late maturity period of oil palm, which might cause the higher ARB and lower $\mathrm{ABW}$, and eventually lead to the decrease of FFB yield. Therefore, the higher MAAT had the lower probability encountering the low temperature when flowering and fruiting, which played a decisive role in improving NB and NFF. MAAT was the major determining factor with the highest positive direct effect on cold resistance of oil palm populations, since there were significant positive correlations among MATT, MAT and ATCM, the lower of them were beneficial to strengthen the cold resistance of oil palm.

\section{REFERENCES}

Barcelos, E; Rios, S De A; Cunha, R N; Lopes, R; Motoike, S Y; Babiychuk, E; Skirycz, A and Kushnir, $S$ (2015). Oil palm natural diversity and the potential for yield improvement. Frontiers in Plant Science, 6 (190): 1-16.

Cao, J H; Li, X B; Lin W F; Xie, G S and Cheng, J M (2009). Survey on resistance of 12 species oil palm cultivated in the field (in Chinese). Chinese J. Tropical Agriculture, 29 (2): 1-6.

Corley, R H V (1992). Yield potential in Colombia. Proc. of the Workshop Yield Potential in the Oil Palm (Rao, V; Henson, I E and Rajanaidu, N eds.). Int. Soc. Oil Palm Breeders, Kuala Lumper. p. 217.

Corley, R H V and Breure, C J (1992). Fruiting activity, growth and yield of oil palm. 1. Effects of fruit removal. Expl. Agric., 28: 99-109.
Corley, R H V and Tinker, P B (2003). The Oil Palm. Fourth edition. Backwell Science Ltd. p. 53-131.

Fan, F C (1982). The climatic conditions in relation to oil palm cultivation on Hainan island (in Chinese). Chinese J. Tropical Crops, 3 (1): 81-93.

Ferwerda, J D (1977). Oil palm. Ecophysiology of Tropical Crops (Alvim, P De T and Kozlowski, T T eds.). Academic Press, London. p. 351-383.

Goh, K J (2000). Climatic requirements of the oil palm for high yields. Managing Oil Palm for High Yields: Agronomic Principles (Goh, K J ed.). Malaysian Soc. of Soil Sci. and Param Agric. Surveys, Kuala Lumpur. p. 1-17.

Cohen, J (1988). Statistical Power and Analysis for the Behavioral Sciences. Second edition. Lawrence Erlbaum Associates, Hillsdale, NJ.

Henson, I E and Dolmat, M T (2004). Seasonal variation in yield and developmental processes in an oil palm density trial on a peat soil: 2 . Bunch weight components. J. Oil Palm Res.Vol. 16(2): 106120.

Lu, M J; Wei, D Y and Wang, K X (1991). Report on hybrid test of oil palm (in Chinese). Tropical Crops Research, 2: 14-21.

Lu, M J; Wei, D Y and Yang, C P (1982). Studies on the adaptability of oil palm in Hainan island (in Chinese). Tropical Crops Research, 1: 72-80.

Tang, Q Y and Feng, M G (2007). DPS CData Processing System (Experimental Design, Statistical Analysis and Data Mining) (in Chinese). Science Press, Beijing.

Wright, S (1923). Correlation and causation. J. Agric. Res., 20: 557-585.

Zeng, X H; Pan, D L; Liu, Z; Chen, J M and Lin, W F (2016). Evaluation of cold tolerant high yielding oil palm germplasm in Guangdong Province of South China, a northern tropical region. J. Oil Palm Res. Vol. 28 (3): 266-280.

Zeng, X H; Zhang, X C and Zou, J X (2015). Studies analysis on the production utilization status and development potential of oil palm in northern tropical regions of China (in Chinese). China Agricultural Science. Science Press, Beijing. 